\title{
O Regresso do morto: oralidade, memória e tradição constituintes da identidade nacional ${ }^{\mathbf{1}}$.
}

\section{Rosilene Silva da Costa*}

\begin{abstract}
Resumo: Este ensaio tem como objeto de estudo o Abstract: This essay aims at analyzing the book $O$ livro $O$ Regresso do Morto, de Suleiman Cassamo, regresso do morto, by Suleiman Cassamo, a autor moçambicano. Serão discutidos alguns aspectos Mozambican author. There will be discussed some da oralidade, memória e tradição como constituintes da aspects of the orality, memory and tradition as identidade nacional. constituents of the national identity.
\end{abstract}

Palavras-Chave: oralidade; memória; tradição; Keywords: orality; memory; tradition; fragmentation; fragmentação; identidade. identity.

\section{Brevíssimo histórico da Literatura Moçambicana}

$\mathrm{O}$ apego à terra é uma característica marcante nos moradores de sociedades rurais. $\mathrm{Na}$ maior parte das sociedades africanas, a vida é rural, o processo de urbanização está ocorrendo gradualmente após as independências e fim das guerras civis, daí a literatura africana ser repleta de cenas de ambientes rurais. Nestes ambientes não urbanizados são guardadas as tradições: expressas no respeito aos mais velhos, na importância da palavra falada (seja no ato de falar agindo no mundo, seja no ato de contar, a fim de modificar ou entender alguma coisa do mundo), na valorização dos elementos da natureza, na reverência aos antepassados falecidos, enfim, em todos os elementos que de alguma forma identificam os grupos formadores de África.

Moçambique é independente desde 1975 e livre da guerra civil desde 1992, ou seja, é uma sociedade que ainda está se acostumando com o fato de ser nação, no sentido moderno.

\footnotetext{
${ }^{1}$ Este texto é uma readaptação do texto $O$ regresso do morto: a vida escondida na obscuridade da morte, apresentado como trabalho de conclusão da Disciplina: Oralidade Memória e Tradição (PPG-Letras/UFRGS) no em 2007/01. Logo após foi comunicado e publicado no III Encontro de Professores Literatura Africana na UFRJ

* Graduada em Letras pela Universidade Federal do Rio Grande do Sul e mestranda do Programa de PósGraduação em Letras da referida universidade, na especialidade Literatura Brasileira, Literatura Portuguesa e Literaturas Luso-africanas. Email: lenecostas@hotmail.com
} 
Está dividida entre a vida rural e a vida urbana. Aqueles que abandonaram o campo, para empreender uma nova vida na cidade, geralmente acabam se afastando dos princípios e costumes da vida rural, os quais são fundamentais na construção da identidade cultural do país.

A assimilação cultural exigida para a ascensão na escala social obriga os moçambicanos a abandonarem suas raízes culturais e religiosas. Para ser assimilado pela cultura branca européia (dominante mesmo após o processo de independência) é necessário falar português, deixando de lado os dialetos do país; estar inserido no mundo letrado e de alguma forma abandonando as raízes da oralidade; e aceitar os dogmas cristãos, contrários aos princípios das religiões locais. Estas e outras práticas produzem um processo de "branqueamento cultural", pois obrigam o africano a deixar suas vivências e aceitar o estilo de vida importado da Europa e de outros lugares.

Este processo de desenraizamento é doloroso, pois, mesmo quando as pessoas optam por uma vida na cidade e de alguma forma aceitam as regras propostas pelo sistema dominante, a dor é sentida: há uma quebra no sistema de valores individuais e grupais. Essa dor está sendo registrada na literatura e nas artes em geral.

As primeiras manifestações literárias nos meados de 1975 tinham o intuito de convocar os moçambicanos leitores e os leitores de literatura moçambicana a repensar as suas posições políticas sobre o país. Nesta época temos a presença de Luis Bernardo Honwana, José Craveirinha e outros, que, através da literatura, levantaram a bandeira da independência, denunciando o estado de abandono e a crise que havia se instaurado com a saída dos portugueses do território moçambicano.

Os anos passaram e outras pessoas surgiram no espaço literário, porém a bandeira agora não é de convocação, mas sim de denúncia, pois Moçambique sofrera um processo de abandono por parte da ONU, durante a guerra civil que assolou o país. Os primeiros livros de Mia Couto e de Noémia de Souza são reveladores dos aspectos históricos deste momento. Em Terra Sonâmbula, Mia Couto (1992) apresenta a situação daqueles que fogem da guerra civil, começando a viver o desapego da terra e da vida rural: "Quero pôr os tempos, em sua mansa ordem, conforme esperas e sofrências. Mas as lembranças desobedecem, entre a vontade de serem nada e o gosto de me roubarem do presente. Acendo a estória, me apago a mim. No fim destes escritos, serei de novo uma sombra sem voz." (COUTO, 1992. p 15)

Quinze anos marcam o fim da guerra civil em Moçambique, o cenário teve algumas modificações, porém as questões relativas à tradição e a terra ainda são importantes. O processo de assimilação não é uma prática tranqüila, pois os moradores do mundo rural ainda 
precisam abandonar suas raízes tradicionais. A literatura continua o seu registro, porém a situação não é de apenas denúncia, o papel dos escritores da atualidade é também o de resistir à imposição da cultura européia. Muitos são os nomes que surgem no cenário da atualidade: Mia Couto continua escrevendo, e talvez seja o mais conhecido escritor moçambicano; Paulina Chiziane tem quatro romances publicados; vários poetas e prosadores têm surgido, entre eles Suleiman Cassamo, autor de quatro livros, publicados em Moçambique e Portugal. É sobre Suleiman Cassamo e seu livro O Regresso do Morto (1997) que passaremos a deter nosso olhar neste ensaio.

\section{Visão panorâmica de $O$ Regresso do Morto (1997)}

O Regresso do Morto é uma coletânea de contos, publicada em 1989 em Moçambique, onde recebeu o Prêmio da Associação dos Escritores. Em 1997 foi publicado em Portugal e já obteve uma tradução para o francês. A obra é marcada por um profundo amor pela terra: a terra vista como a mãe, como símbolo de vida e guardiã dos ancestrais. $\mathrm{O}$ autor dedica o livro aos seus pais: "A meus pais: porque o sangue é veículo da memória” (CASSAMO,1997 p.07).

Já na dedicatória do livro percebe-se a importância dos antepassados, marcada não só na dedicatória aos pais, mas principalmente na maneira como se refere ao sangue e à memória. A memória, ao ser conduzida pelo sangue, simboliza a vitalidade e força contida num passado; o sangue, veículo da memória, deixa de ser apenas o elemento natural do ser humano, assume o compromisso de transmitir às gerações vindouras o passado de uma família, comunidade, ou nação.

Há, na abertura do livro, uma mensagem aos leitores, onde o autor expressa o que deseja oferecer através de seu livro: "Que da leitura destes contos vos fique um leve, levíssimo sabor a terra. O sabor da nossa terra" (CASSAMO,1997, p.09). Talvez a principal pergunta que nos surja desta nota inicial seja: “Quem é este leitor?”. Uma primeira tentativa de resposta, talvez aponte para um leitor não-moçambicano. Pensamos, porém que o escritor se refere tanto ao leitor estrangeiro, quanto ao leitor nacional, pois o livro se presta a dar um sabor da terra: uma oportunidade para o estrangeiro degustar, e para o moçambicano um renovo em seu prazer. Inferimos que a literatura, neste caso, o livro de CASSAMO (1997), passa a ser "um molho" que, além de incrementar o sabor, faz aumentar o apetite por um alimento já conhecido - a terra de Moçambique.

Os dez contos que compõem o livro trazem aspectos da vida urbana e rural. Ao apresentar a vida nas cidades, o autor ora apresenta os moradores bem sucedidos, ora os 
habitantes das periferias, com suas tristezas ou dificuldades. Nestes contos, o autor marca a ambigüidade da vida urbana, que impõe o afastamento das tradições, mas não consegue eliminar, com os encantos da pós-modernidade, os conhecimentos e saberes tradicionais.

A temática central do livro é a morte, que ora representa o fim natural da vida, ora simboliza as dificuldades e percalços cotidianos. Um segundo tema que pode ser apreendido é a situação da mulher: o autor apresenta as mulheres como portadoras de força motriz na sociedade. Pensamos que as mulheres podem significar vida, se opondo, desta forma, à morte.

Os contos são curtos, apenas um é narrado em primeira pessoa, tendo um aspecto epistolar - o narrador é claramente culto e assimilado. Os outros nove contos são narrados em terceira pessoa, dando-nos a sensação de estar diante de um contador de histórias. Os elementos da natureza são constituintes do universo literário africano, pois as culturas africanas estabelecem uma relação de valoração e intimidade com a natureza. Em O Regresso do morto isso não é diferente, porém o autor escolhe o elemento terra como principal em suas narrativas.

Após uma brevíssima revisão da história literária de Moçambique, e uma visão panorâmica da obra O Regresso do Morto, buscaremos assinalar aspectos relevantes da tradição, da oralidade e da memória, expressos nesta obra. Dividiremos nossa análise em duas partes: primeiramente pensaremos sobre os movimentos da tradição na sociedade moçambicana; logo após, discutiremos alguns aspectos relativos à memória e à oralidade na constituição da identidade do país.

\section{Os movimentos da tradição na sociedade moçambicana}

Zygmunt Bauman (1999) postula que a modernidade é marcada por uma profunda ambivalência, ou seja, pela presença concomitante de juízos contraditórios sobre o mesmo objeto. Os indivíduos modernos são atraídos simultaneamente por dois impulsos opostos, deixando-os sem saber qual adotar. Esse desejo de atender a ambos os impulsos, coloca o sujeito num constante estado de tensão e de indecisão. A dúvida gera a divisão, advindo daí uma das palavras chaves da modernidade: fragmentação. A sociedade moderna, fragmentada, apresenta um homem cindido em seus conceitos, tornando-o agitado, inquieto ou paralisado, pois não pode se firmar naquilo que acredita, visto que, muitas vezes é ultrapassado, e, no entanto, não sente segurança diante do novo porque ainda o desconhece. O tempo presente se constitui em verdadeira guerra, onde passado e futuro lutam, sendo perdedor no conflito o homem moderno. 
A obra de CASSAMO (1997) nos apresenta este homem cindido que habita os diversos lugares de Moçambique. Em muitos contos de O Regresso do Morto, este sujeito fragmentário aparece, mas cremos que o mais chocante e que melhor exemplifica essa fragmentação da modernidade é o conto "Madalena, xiluva do meu coração". Fabião (narrador e protagonista do conto) abandonou sua terra, suas raízes e seu amor em busca da vida na cidade e da assimilação cultural: em troca recebeu a tristeza de nem ao menos ter coragem para escrever uma carta à mulher que ama. Esta personagem exemplifica a distância que existe entre o mundo urbano e rural, e o quanto dói estar inserido na cultura moderna. Fabião, ao ser assimilado, passa a atender pelo nome de Neves e a ter costumes de branco. Não pode assim dedicar seu amor à Madalena, já que ela ficou no campo e é ignorante no ambiente urbano. Ao justificar o abandono de Madalena, desculpa também à abdicação das tradições, pois, de certa forma, ele fora obrigado a recusar suas raízes, a fim de ver o país crescer e acompanhar o desenvolvimento. Fabião e Neves exemplificam a cisão ou fragmentação da modernidade, a ambivalência de conceitos num mesmo sujeito. Em um mesmo corpo habita o Fabião, que ama Madalena, as tradições, e a terra; mas há também o Neves, que reconhece que, "Estudar é ainda necessário. Fabião busca nos livros o saber para forjar o ferro da tua enxada, o cobre para tuas pulseiras de Nhancuave, teu nome de criança que vem dos avôs-dos-avôs, para fazer o teu sabão, o pente e sapatos para pôr e vir no Xilunguini." (CASSAMO, 1997 p. 42).

A tradição (do latim traditio, significa entrega) resiste em muitos outros aspectos do cotidiano moçambicano: no significado dos sonhos, na aparição de fantasmas, na expressão dos elementos da natureza, etc. O conto "Vovó Velina" é outro revelador deste traço ambivalente dos sujeitos, visto que um casal assimilado, da cidade, espera um bebê. Presumese que por viverem no ambiente urbano e serem letrados têm condições de saber o sexo do bebê por meios modernos, porém a personagem mãe revela: "Mamana, não falta muito vou ter bebé. Sonhei, vai ser minina xonguile parece xiluva e xiphatiphati parece nyeleti. Nome dela vai ser Velina".(CASSAMO, 1997. p. 71). Embora a vida da cidade tenha furtado muitas crenças tradicionais do casal, conforme o narrador do conto nos apresenta, ela não consegue apagar o sentido que os sonhos têm nesta cultura. Nas culturas tradicionais, os sonhos não são apenas os postulados freudianos: expressão do subconsciente. Eles assumem o papel de vidente ou profeta, visto que são anunciadores de coisas boas ou más. O sonho tanto revela o sexo do bebê, trazendo a boa notícia que muda o ânimo de Vovó Velina, quanto é portador de maus agouros, como podemos ver no conto "José, pobre pai natal". Neste conto é através do 
sonho, chamado de pesadelo, que a personagem Maria vê prenunciada a morte de seu marido José:

Levava uma bacia na cabeça e gritava: Ama-rhumbo! Ama-rhumbo! Ama-rhumbo!... Ia a todo lado e ninguém comprava. Fechavam portas e janelas, fugiam dela. A bacia crescia e pesava na cabeça. Cansada, regressou. Pôs a bacia no chão. Oh, o que ela não viu!...

-Em vêgi de tripa, um morto, Senhora. A rir-me com dentes assim!... (CASSAMO, 1997. p. 60)

Mencionamos que o autor estabelece, a partir do nosso ponto de vista, uma oposição entre vida e morte, sendo a vida expressa nas personagens femininas. Laurinda, personagem central, do segundo conto do livro, é moradora da periferia. Laurinda precisa levar pão para sua família - e isto quase lhe custa a própria vida e a dignidade, porém vemos inscrita nesta mulher uma força capaz de superar os maiores obstáculos para preservar a família e a si mesma. Em sua espera pelo pão, ela faz reflexões sobre a vida cotidiana, e intervém nas situações corriqueiras indicando a força e o desejo que tem de manter-se honesta, mesmo quando está em jogo a sobrevivência de sua família.

Laurinda mordeu, outra vez, o lábio, com força. Sentiu o sangue na língua. Que o sangue sabia a sal, há muito, sabia. Mas misturado com raiva tinha um sabor novo, um sabor de merda. Explodiu:

-Sacana! Eu não me vende com pãozinho! Eu não é puta, ouviu? Tem marido, tem filhos, eu. Eu... eu... - batia com a mão no peoti - eu não é cadela , ouviu? Você és moluene! Vai-te subir, moluene! Mbuianguana! Agora qu'star massar tricô quer dormir com mulher de dono. Não tem virgonha. ( CASSAMO, 1997 p. 23)

O autor registra o idioma de Laurinda: o português, língua oficial de Moçambique, porém repleto de expressões das línguas locais. Este imbricamento de línguas assinala mais um ponto de resistência das culturais tradicionais à imposição da modernidade. A convivência das diversas línguas em Moçambique sabe-se que ainda não é harmônica, pois é necessário falar português, mas segundo o Professor Lourenço do Rosário:

Da mesma maneira que o português no Brasil, com toda a sua plasticidade, consegue hoje, responder e corresponder à tropicalidade do brasileiro, o português africano (de cada país africano), se for amparado e acompanhado, poderá saber representar e bem a ritmicidade africana. (ROSÁRIO, 2007 p.13)

A temática feminina está presente em vários contos desta obra, embora o autor não dê voz a essa mulher, suas histórias sempre aparecem na voz do narrador. Inferimos que o narrador, pelo distanciamento que tem das personagens femininas, é um sujeito masculino. $\mathrm{O}$ conto que abre livro evoca a prática do tradicional lobolo, na qual o homem oferece alguns bens à família da esposa, tornando-se assim proprietário dela. Ao marcar a experiência do lobolo, mais recorrente nas camadas mais pobres, a narrativa demonstra a existência de dois 
discursos antagônicos: o discurso feminista, contrário à coisificação da mulher, e o discurso tradicional resistindo a esse e a outros discursos.

Um ano passou. O marido começou com zangas. Diz Nglina não nasce filhos. Não sabe porque a lobolou. Não é mulher. Batea-a por tudo e por nada. Com cinto que tem ferro, com paus, com socos , com pontapés, com tudo. Coitadinha, Nglina, era uma minina xonguile mas agora ficou velha num ano só. Ngilina é xiluva que murclhou.

O corpo dói, sim, mas dói é muito muito o coração. O coração 'sta inchado, vai rebentar no peito. Nglina, tu vai morrer. Pode ir para casa descansar sofrimento. Mas qual manera se o pai comeu todo o dinheiro do lobolo no nhonthontho e no vinho do monhé da vila? Yotatanéé, é melhor não pensar nada. (CASSAMO, 1997 p. 17)

A personagem central desta narrativa não parece ser uma mulher consciente de que nela estejam impressos conceitos divergentes sobre a constituição familiar, especificamente a feminina, porém ela vive o conflito comum do homem moderno, o qual apontamos no início desta sessão: a cisão. Ela acaba conseguindo sua liberdade, infelizmente, através da morte.

Os mitos e histórias de Moçambique são registrados ao longo dos contos. Em vários momentos eles aparecem, demonstrando que este processo de modernização e assimilação cultural pode até conseguir furtar algumas pessoas das suas origens, mas não é capaz de apagar delas as marcas impressas pela memória.

O conjunto de contos nos coloca em volta da fogueira, diante do griot (contador de história). Em muitos contos o narrador se transforma no contador de histórias, conforme veremos adiante, ao falarmos sobre oralidade. Esse movimento da literatura, ou seja, do escrito, demonstra, novamente, o sujeito ambivalente. $\mathrm{O}$ escritor recria no seu narrador a figura do contador tradicional, o que nos mostra que, junto da necessidade de belas histórias escritas, convive a necessidade de belas histórias faladas.

A terra constitui um elemento importantíssimo para o conjunto de contos de CASSAMO (1997), pois os homens mantêm uma ligação profunda com ela. A terra representa a mãe geradora de vida, ao mesmo tempo em que é aquela que encerra um ciclo de vida para dar início a outro na morte. Esta terra, sagrada para a maior parte dos africanos, tem sido furtada no processo de urbanização e de assimilação cultural do país. O autor registra este movimento de desapego dos homens a sua mãe terra, conseqüentemente às suas tradições. Em "O regresso do morto" (conto que nomeia o livro) vimos que a personagem principal parte para trabalhar na cidade, ainda muito jovem. O moço sai da sua terra sem a menor reverência às suas raízes, pois nem mesmo se despede de sua mãe. Ao regressar (após a noticia de sua suposta morte) não tem o reconhecimento dos seus, causa espanto, torna-se um fantasma naquele mundo, porém a mãe, representando a terra e as tradições, o reconhece. 
Queremos fechar esta parte do trabalho contrapondo dois conceitos: o moderno de BAUMAN (1999) e o tradicional, proposto por CASSAMO (1997) no conto "O regresso do morto”. BAUMAN (1999) após analisar os tempos modernos, aponta a pós-modernidade como saída, mas não consegue ser otimista. O professor ocidental afirma: "o que é realmente novo na nossa atual situação, em outras palavras, é o nosso ponto de observação".(BAUMAN, 1999, p. 288) Desta forma ele não dá muitas expectativas para o homem livrar-se do conflito imposto pela ambivalência de conceitos. Cassamo (também professor universitário em Moçambique), através do narrador em "O regresso do morto", diz que, quando o jovem fitou sua mãe rachando lenha, “o fogo avivou os olhos mortos" (CASSAMO, 1997 p.82). Vemos nisso uma metáfora de vida e de liberdade que o regresso à casa e às tradições pode dar ao homem. Estamos diante de dois conceitos, não poderia ser diferente em tempos modernos ou pós-modernos, cabe a cada um fazer sua opção.

\section{Memória e Oralidade na identidade cultural moçambicana}

“A memória é a mais épica de todas as faculdades" (BENJAMIN, 1985, p. 210): sendo assim, é forma discursiva que recria e fixa vivências, transformando-as em interpretações que atravessam tempos e desdobram realidades. Desta forma, o passado pode apresentar diversas versões, está instalado entre a memória e a história e encontra na linguagem a sustentação que "reduz, unifica e aproxima no mesmo espaço histórico e cultural a imagem do sonho, a imagem lembrada e as imagens da vigília atual" (BOSI, 1996, p.56).

Para os africanos, particularmente, a memória tem um papel fundamental para a preservação da cultura, pois na África a tradição e a história foram, durante muito tempo, repassadas aos jovens, basicamente, por via oral, assim a ausência de memória equivaleria à perda de parte da história e das tradições. Os velhos são os cronistas dos acontecimentos que devem ser passados aos jovens. Ao contarem as histórias passadas, eles asseguram o viver da tradição. A figura do contador de histórias passa a um lugar de destaque, pois nela se encerram não apenas os saberes que precisam ser repassados, mas também as formas de repasse. O contador de histórias (griot) tem um papel que vai além do contar, visto que ele também deve formar outros contadores, pois, deste modo, garantirá a perpetuação das tradições.

Ao nos voltarmos para a obra O regresso do morto de CASSAMO (1997), percebemos este cuidado, ou seja, o autor instala, na figura do narrador, a responsabilidade de perpetuar a tradição. Como falamos na abertura de nosso texto, o início do livro (dedicatória e epígrafe) já 
aponta para isso, mas é na figura do narrador que o autor consolida o seu projeto. O narrador de Cassamo seduz o leitor de forma que este tem desejo de ouvi-lo, é impossível a realização da história sem a sua voz. Há interação entre o narrador/contador e os seus leitores/ouvintes: homens, mulheres ou crianças o ouvirão com atenção, pois ele cria um ambiente que permite muitas leituras e aprendizados com uma única história. O conto "Nyeleti" exemplifica isto.

Esse conto trata de uma temática básica: dois jovens disputando o amor de uma moça. Um é amado, o outro rejeitado. $\mathrm{O}$ amado parte para fazer fortuna, e o rejeitado aproveitando a ausência dele, usa um feitiço que encanta a jovem, e esta casa com ele. Quando o amado retorna, há uma disputa, e o final não é feliz, pois a moça acaba ficando sem nenhum dos dois.

O narrador seduz o leitor, instaurando um clima poético, pois as personagens e seus atos são descritos a partir de metáforas da natureza. Na abertura do conto, ele convida o seu interlocutor a prestar atenção numa papaieira, com isso ele exemplifica o espaço de sua história. O narrador nos coloca tanto na posição de ouvintes, sentados no chão, quanto na posição de leitores que podem imaginar o cenário. Queremos nos ater, contudo, às inúmeras temáticas possíveis de serem depreendidas desta história. Sabemos que muitos são os sentidos que um texto pode ter, mas, particularmente neste conto, pensamos em alguns sentidos pedagógicos que podem ser transmitidos numa contação para público misto. Há toda uma crítica à partida do jovem amado, pois este abandona sua terra e sua amada para ir em busca de dinheiro, assim desvincula-se das tradições, abrindo espaço para que o segundo entre em jogo. Malatana, o rejeitado, tenta seduzir Nyeleti, porém não é bem sucedido, então decide partir e buscar artifícios religiosos: o feitiço. Assim o rejeitado passa a amado, porém, não age de forma honesta, pois ele sabe que a jovem não o ama e que já fora firmado um compromisso de lobolo. Nyeleti também erra, pois na ausência do amado ficara ouvindo a voz de Malatana, ou seja, deixando que seu coração tivesse esperanças, quando ela estava comprometida com o jovem Foliche.

Em "Nyeleti", o narrador, nos fala do respeito às entidades sagradas da natureza, pois é na floresta e nas águas que Malatana busca o feitiço. Ao descrever Foliche voltando agressivo como um tsotsi, relembra que o país é formado por diversos grupos, cada um com suas características. O conto é pedagógico, no sentido de ensinar aos mais jovens algumas tradições: cuidado com a natureza, pois ela abriga o sagrado; o uso do feitiço não pode ser de qualquer forma; o poder da palavra está acima de tudo, pois havia compromisso de lobolo, o qual foi quebrado quando Nyeleti abandonou a casa dos pais para viver com Malatana. Independente de quem seja o público, o conto se presta a ensinar alguma coisa, seja para uma 
moça ou para um moço que deseje casar, ou ainda para uma criança ou um velho, que ouvirá a história pelo seu encanto de ser história.

Ana Mafalda Leite (1998) prefere usar o termo oralidades, que permitiria dar conta de diferenciar a maneira como os escritores se relacionam com as histórias orais e com as línguas. Ela postula que existem três tipos de apropriação da oralidade: oralizar a língua portuguesa; hibridizar, através da recriação sintática e lexical; ou interseccionar com as diferentes línguas africanas. Percebemos que Cassamo faz uso da intersecção, pois ele constrói as frases usando palavras de diferentes línguas. Faz uso de onomatopéias, e escreve algumas palavras de forma que venham marcar cada segmento do texto com um ritmo diferenciado. Além disso, o escritor insere palavras inglesas nos textos, as quais, geralmente, são usadas nas atividades financeiras de compra e venda de produtos ou de força de trabalho. Ao final do livro é inserido um glossário, pois a ausência deste impossibilitaria aos de fora terem uma boa compreensão do texto.

As estratégias narrativas usadas pelo autor combinam elementos da modernidade e da tradição. Da modernidade, usa a fragmentação: seja nos aspectos lingüísticos, seja na construção das histórias; da tradição, recupera os aspectos culturais fundamentais, ao mesmo tempo em que questiona as heranças negativas ainda presentes na sociedade moçambicana. Cassamo, através deste narrador, se constitui contador de histórias, inscrevendo em seus textos uma visão crítica tanto do contexto social, quanto da própria arte de narrar e escrever.

Pelo viés de Stuart Hall (2006), uma das figuras mais importantes na área de estudos sociais da atualidade, uma cultura nacional é uma comunidade imaginada. As nações são formadas por diversos povos, logo abrigam diversas culturas. Em cada nação há uma cultura dominante, e geralmente, a sua dominação se dá ou se deu, através de processos violentos. Ao discutirmos a identidade de uma nação, "devemos ter em mente a forma pela qual as culturas nacionais contribuem para 'costurar' as diferenças numa única identidade”. (HALL, 2006 p. 65)

O contexto africano, mais especificamente moçambicano, vive este processo de luta para a construção desta cultura nacional. A literatura tem registrado os inúmeros embates culturais que o país tem vivido. Ao olhar a obra de Cassamo, e através dela, pensarmos este momento de construção da identidade nacional, verificamos que a sociedade atual tem lutado contra a globalização, que tenta exterminar todas as culturas. Sabemos que a luta é desigual, e que a oponente globalização possui armas poderosas, porém Stuart Hall (2006, p. 58) nos aponta que "as memórias do passado; o desejo por viver em conjunto; a perpetuação da herança" são os conceitos constituintes de uma comunidade imaginada. 
A Literatura, junto com outras artes e em parceria com algumas ciências, tem buscado construir esta comunidade imaginada. Na obra de CASSAMO (1997), percebemos que há voz para homens e mulheres, não fazendo distinção de gêneros; espaço para jovens e velhos, abrindo mão dos preconceitos de idade; ambiente para brancos e negros, independente dos julgamentos errôneos a respeito de raça; discussão dos diversos grupos culturais e religiosos do país, sem julgamento de superioridade ou inferioridade; convivência de oralidade e escrita, não atribuindo a uma ou outra, aspectos mais ou menos positivos; e por fim, lugar para modernidade e tradição, discutindo as contribuições de ambas para uma vida melhor.

A memória e a oralidade, desta forma, contribuem para o processo de construção da identidade moçambicana, no momento em que homens e mulheres falam como Lucas, personagem central do conto Casamento de um casado: “- É do meu primeiro casamento: lutar pela nossa terra!" (CASSAMO, 1997 p.77)

\section{Harmonia contraditória: palavras finais}

O movimento de regresso às tradições e a terra é a ênfase desta obra de Suleiman Cassamo. Nela o autor apresenta uma mescla de culturas que dividem o mesmo espaço: Moçambique. Através do hibridismo cultural ele procura afirmar uma identidade nacional moçambicana: é na diversidade cultural do país que o autor encontra os ingredientes de seus contos, que darão novo sabor à terra.

Benjamin postula que é necessário que a história seja desvendada, não apenas os fatos históricos que se encontram registrados nos livros oficiais, mas também aqueles que correspondem aos relatos orais do povo. Segundo ele, é preciso recuperar o imaginário dos oprimidos, armazenado nos mitos, nas lendas, nas crenças e nos testemunhos orais. Percebemos que Cassamo busca, através da memória, recuperar os fatos importantes da história e da tradição moçambicana. $\mathrm{O}$ autor promove um encontro de culturas ao colocar num mesmo espaço, o livro: as histórias do patrimônio oral e os relatos das dificuldades cotidianas da vida no campo ou na cidade.

A concepção de tradicional na obra de Cassamo não pode ser compreendida como conservadorismo simplesmente, visto que ela abre espaço para o desenvolvimento de uma outra versão da História de Moçambique, contada e experimentada pelos sujeitos cindidos que a (pós) modernidade tem criado. Aos leitores/ouvintes resta decidir entre os encantos modernos e a tradição; ou ainda buscar este "novo", fusão do moderno e do tradicional, que é proposto por Homi Bhabha: 
O trabalho fronteiriço da cultura exige um encontro com o "novo" que não seja parte de um continuum de passado e presente. Ele cria uma idéia do novo como ato insurgente de tradução cultural. Essa arte não apenas retoma o passado como causa social ou precedente estático; ela renova o passado, refigurando-o como um "entre-lugar" contigente, que inova e interrompe a atuação do presente. O "passado-presente" torna-se parte da necessidade, e não da nostalgia de viver. (BHABHA, 2007 p.27)

A construção de identidades nacionais modernas, a partir do que expusemos, deve privilegiar o contato dos diferentes, numa relação de paridade. A literatura e as artes têm apontado para a existência de uma harmonia entre idéias contraditórias. Cremos que, apesar de parecer uma idéia romântica, essa é a única porta para um mundo "pós-moderno" melhor.

\section{Referências}

BAUMAN, Zigmunt. Modernidade e ambivalência. Rio de Janeiro: Ed. Jorge Zahar, 1999.

BENJAMIN, Walter. KOTHE, Flávio (Org.). Walter Benjamin. São Paulo: Ática, 1985 (Coleção Grandes Cientistas Sociais).

BHABHA, Hommi. O local da cultura. Belo Horizonte: Ed. UFMG, 2000.

BOSI, Ecléa. Memória e sociedade: lembranças de velhos. São Paulo: Companhias das Letras, 1996.

CASSAMO, Suleiman. O regresso do morto. Lisboa: Ed. Caminho, 1997.

COUTO, Mia. Terra Sonâmbula. Lisboa: Caminhos, 1992.

HALL, Stuart. A identidade cultural na Pós-modernidade. Rio de Janeiro: DP\&A, 2006.

LEITE, Ana Mafalda. Oralidades e escritas nas literaturas africanas. Lisboa: Colibri, 1998.

MOREIRA, Terezinha Taborda. $O$ vão da voz: a metamorfose do narrador na ficção moçambicana. Belo Horizonte: Ed. PUC-Minas, 2005.

ROSÁRIO, Lourenço. Singularidades II. Maputo: Texto Editores, 2007. 